\title{
The Arabian horse SCIDs to a halt
}

\author{
SCIENTIFIC NAME \\ Equus ferus caballus \\ TAXONOMY \\ PHYLUM: Chordata \\ CLASS: Mammalia \\ SUBCLASS: Theria \\ INFRACLASS: Eutheria \\ ORDER: Perissodactyla \\ FAMILY: Equidae
}

\section{Breed history}

The Arabian horse takes its breed name from its location of origin: the Arabian Peninsula. It is one of the oldest horse breeds, with some evidence suggesting it has existed for almost 4,000 years ${ }^{1}$. Originally developed in a desert climate and used in both war and trade activities, the Arabian is a good-natured yet high-spirited breed with speed, alertness, intelligence and endurance. Because of its close association with humans, it has been selectively bred to emphasize its pleasant disposition and temperament.

\section{Physical description}

The Arabian is one of the most recognizable breeds of horse, largely because of its characteristic morphology. Arabian horses have wedge-shaped heads with large eyes, large nostrils and small muzzles. They have arched necks with prominent windpipes. Most Arabians possess a distinctive concave spinal profile, enhanced by a relatively long, level croup (top of the hindquarters) and a naturally high tail carriage. They have a compact body and stand 57-61 in (14.1-15.1 hands) tall. Their bones are dense and strong, but their bone structure is very refined. The coat color is most commonly bay, gray or chestnut; black is less common. The skin is almost always black, except underneath white markings.

\section{Genetic susceptibility}

Arabian horses are susceptible to several genetic disorders, including severe combined immunodeficiency (SCID) ${ }^{2}$, which also occurs in humans. In Arabian horses, the disorder is inherited in an autosomal recessive fashion ${ }^{3}$, fatal in homozygotes but asymptomatic in heterozygous carriers. Foals with SCID are born completely lacking an immune system, like the 'bubble boy,' and typically succumb to opportunistic infection before the age of 3 months (ref. 2). Since the development of a DNA test to detect the mutation in healthy carriers ${ }^{4}$, however, horses can now be screened before mating to minimize the number of foals born with SCID ${ }^{5}$.

\section{Research résumé}

The first cases of SCID in Arabian horses were reported in 1973 (ref. 6). Arabians became the first animal models of SCID, and affected foals were used in studies investigating the pathology and molecular basis of the disease as well as testing potential therapies, such as bone marrow transplants ${ }^{7}$. But when it was later discovered that the genetic mutations leading to SCID were not the same in humans and horses ${ }^{8}$, Arabians were largely replaced with other animal models with disease characteristics that more closely recapitulated the human disorder, including mice and dog breeds such as the basset hound and the Welsh corgi ${ }^{9}$.

Arabian horses are also used in studies of exercise physiology, energetics and acclimatization to high altitude ${ }^{10,11}$.

1. Upton, P., van Lent, R. \& Amirsadeghi, H. Arabians (Chronicle Books, San Francisco, CA, 1999).

2. Suddert, M.J. Primary, severe, combined immunodeficiency disease of Arabian foals. Aust. Vet. J. 54, 411-417 (1978).

3. Perryman, L.E. \& Torbeck, R.E. Combined immunodeficiency of Arabian horses: confirmation of autosomal recessive mode of inheritance. J. Am. Vet. Med. Assoc. 176, 1250-1251 (1980).

4. Shin, E.K., Perryman, L.E. \& Meek, K. Evaluation of a test for identification of Arabian horses heterozygous for the severe combined immunodeficiency trait. J. Am. Vet. Med. Assoc. 211, 1268-1270 (1997).

5. Tarr, C.J., Thompson, P.N., Guthrie, A.J. \& Harper, C.K. The carrier prevalence of severe combined immunodeficiency, lavender foal syndrome and cerebellar abiotrophy in Arabian horses in South Africa. Equine Vet. J. doi:10.1111/ evj.12177 (published online 3 September 2013).

6. McGuire, T.C. \& Poppie, M.J. Hypogammaglobulinemia and thymic hypoplasia in horses: a primary combined immunodeficiency disorder. Infect. Immun. 8, 272-277 (1973).

7. McCarthy, K. Arabian horse research offers clues to disease. Palm Beach Post (14 April 1983).

8. Wiler, R. et al. Equine severe combined immunodeficiency: a defect in V(D)J recombination and DNA-dependent protein kinase activity. Proc. Natl. Acad. Sci. USA 92, 11485-11489 (1995).

9. Perryman, L.E. Molecular pathology of severe combined immunodeficiency in mice, horses, and dogs. Vet. Pathol. 4, 95-100 (2004).

10. Greene, H.M. et al. Metabolic and osmoregulatory function at low and high (3800 m) altitude. Equine Vet. J. Suppl. 34, 545-550 (2002).

11. Greene, H.M., Hurson, M.J. \& Wickler, S.J. Haematological and respiratory gas changes in horses and mules exercised at altitude $(3800 \mathrm{~m})$. Equine Vet. J. Suppl. 36, 551-556 (2006). 